\title{
1982
}

Danvers, Mass.

Tsukuba, Japan

Palisades, N.Y.

Chicago, Ill.

Los Angeles, Calif.

Palisades, N.Y.

San Francisco, Calif.

DEC. 6-10

New Orleans, La.

New Orleans, La.

New Orleans, La.

Lake Tahoe/Incline

Village, Nev.

Cambridge, Mass.

Boston, Mass.

Boston, Mass.

Boston, Mass.

Toronto, Ont.

Ft. Collins, Colo.

Ft. Collins, Colo.

Ft. Collins, Colo.

Banff, Alta.

Detroit, Mich.

Baltimore, Md.

Norman, Okla.

Omaha, Nebr.

Omaha, Nebr.

Ithaca, N.Y.

Logan, Utah
1983

OCT. 17-20

OCT. 18-22

OCT. 25-27

NOV. 15-18

NOV. 29-DEC. 3

DEC. 1-3

JAN. 10-14

JAN. 10-14

JAN. 11-13

JAN. 12-14

MAR. 21

MAR. 22-25

MAR. 22-25

MAR. 22-25

A PR. $11-15$

A PR. 25-29

A PR. 25-29

A PR. $25-29$

MAY 3-5

MAY 26-31

MAY 30-JUNE 3

MAY 31-JUNE 3

JUNE 6-9

JUNE 6-9

JUNE 13-15

JUNE 19-24
With A PCA Conference on Receptor Models Applied to Contemporary Pollution Problems

With WMO Regional Scientific Conference on Tropical Meteorology and Centennial of Meteorological Society of Japan (MSJ)

Ewing Symposium on Climate Processes Sensitivity to Solar Ir radiance and $\mathrm{CO}_{2}$

*Conference on Cloud Physics

Fourth Conference on Precipitation Scavenging, Dry Deposition, and Resuspension

International Symposium on Milankovitch and Climate: Understanding the Response to Orbital Forcing

With AGU Fall Meeting

*63rd AMS Annual Meeting

* Second Conference on Climate Variations

*Conference on Climate/Energy Interactions with DOE

With the Optical Society of America's Topical Meeting on Meteorological Optics

With MIT Jule Charney Celebration

*Sixth Symposium on Turbulence and Diffusion

*Fourth Conference on Atmospheric and Oceanic Waves and Stability

*Fourth Conference on the Meteorology of the Upper Atmosphere

*Fifth Symposium on Meteorological Observations and Instrumentation with CMOS

* 16 th Conference on Agriculture and Forest Meteorology

*Sixth Conference on Biometeorology and Aerobiology

* Seventh Conference on Fire and Forest Meteorology with SAF

17 th Annual Congress of CMOS

With 149 th AAAS Annual Meeting

With AGU Spring Meeting

*First Conference on Mesoscale Meteorology

*Sixth Conference on Numerical Weather Prediction

*Ninth Conference on Aerospace and Aeronautical Meteorology

International Symposium on Gas Transfer at Water Surfaces

With Joint Annual Meetings of AAAS (Pacific Division) and AAAS (Southwestern and Rocky Mountain Division)

\footnotetext{
* Meet ings administered by AMS. Other meetings AMS cosponsors or cooperates.
} 
Evanston, Ul.

Fa ir banks, Alaska

Sao Jose dos Campos, Brazil

Boulder, Colo.

Hamburg, F.R.G.

Oxford, England

Paris, France

Edmonton, Alta.

Sacramento, Calif.

Lisbon, Portugal

Tulsa, Okla.

Tulsa, Okla.

Baltimore, Md.

Hot Springs, Ark.

Hot Springs, Ark.

New Delhi, India

San Francisco, Calif.
JUNE 27-JULY 1

JULY 18-22

JULY 31-AUG. 6

AUG.

AUG. 15-27

AUG. 29-SE PT. 3

AUG. 30-SE PT. 2

SE PT. 19-23

SE PT. 19-23

SE PT. 26-30

OCT. 17-20

OCT. $18-20$

OCT. 31-NOV. 3

NOV.16-18

NOV. 16-18

NOV. $27-30$

DEC. 7-15
With IGS Symposium on Ice and Climate Modeling

Fourth International Conference on Permafrost

*First International Conference on Southern Hemisphere Meteorology

* Short Course on Instruments and Techniques for Probing the Atmospheric Boundary Layer

XVIII General Assembly of the International Union of Geodesy and Geophysics (IUGG)

Fif th International Symposium of the IAMA P Commission on Atmospheric Chemistry and Global Pollution

With IAMA P/WMO Symposium on Maintenance of the QuasiStationary Components of the Flow in the Atmosphere and in Atmospheric Models

*21st Conference on Radar Meteorology

With WMO/NOAA International Technical Conference on Mitigation of Natural Hazards Through Real-Time Data Collection Systems and Hydrological Forecasting

Second International Meeting on Statistical Climatology

*13th Conference on Severe Local Storms

*Fif th Conference on Hydrometeorology

*Fifth Conference on Atmospheric Radiation

*Eighth Conference on Probability and Statistics in Atmospheric Sciences

*Third Conference on Applied Climatology

With ISB International Conference on Biometeorology

With AGU Fall Meeting

*Meet ings administered by AMS. Other meetings AMS cosponsors or cooperates.

New Meeting Procedures for Authors

(for meetings administered by AMS)

For meetings that have preprint or extended abstracts volumes, only reviewer's abstracts will be required; abstracts will not be published in the BULLETIN.

For meetings that do not have preprint or extended abstracts volumes, both reviewer's abstracts and short abstracts (100 words) for inclusion in an abstract booklet to be distributed at the meeting will be required.

Because of time constraints and escalating costs, AMS will no longer accommodate changes in authors' names, affiliations, paper titles, and/or abstracts once the program has been received at AMS from the program chairman.

Programs are now set by computer. Mathematical/chemical equations and/or symbols may not be used in titles and short abstracts. Please substitute words, phrases, or sentences for mathematical and chemical expressions.

Authors are requested to comply with the above procedures. 
APCA CONFERENCE ON RECEPTOR MODELS APPLIED TO CONTEMPORARY POLLUTION PROBLEMS, OCTOBER 17-20, 1982, DANVERS, MASS.

An International Specialty Conference on Receptor Models Applied to Contemporary Pollution Problems will be held 17-20 October 1982 at the Radisson Ferncroft Hotel in Danvers, Mass. The conference is sponsored by the APCA TP-5 Technical Coordinating Committee and is hosted by the APCA Northeast Atlantic International Section. AMS is a cooperating society.

Technical sessions include: Potential uses of receptor model concepts in government and industry, Receptor model validation studies, Urban-scale studies and new model developments, Receptor model measurement methods, and Acid precipitation and long-range transport studies.

Questions on the program should be directed to the Technical Program Chairman: Stuart L. Dattner, Texas Air Control Board, 6330 Highway 290 E, Austin, Tex. 78732 (tel: 512-451-5711). For further general information, contact the General Chairman: Robert A. Boiselle, Massachusetts State Air Quality Section, 1 Winter St., Boston, Mass. 02108 (tel 617-292-5609).

WMO REGIONAL SCIENTIFIC CONFERENCE ON TROPICAL METEOROLOGY, OCTOBER 18-22, 1982, TSUKUBA, JA PAN

A Regional Scientific Conference on Tropical Meteorology will be held 18-22 October 1982 in Tsukuba, Japan, in commemoration of the Centennial of the Meteorological Society of Japan. The Meteorological Society of Japan will host the conference with cooperation of the World Meteorological Organization, the American Meteorological Society, and the Japan Meteorological Agency.

The purpose of the conference is to provide a forum for papers and ideas concerning scientific research and applications on meteorological aspects of phenomena extending from planetary to cumulus scales in the tropics. The International Program Committee plans to include the following topics in the conference program: 1) monsoon and general circulation of the tropics, 2) tropical cyclones and distrubances, 3) air-sea interaction and boundary layer over the tropical ocean, 4) interaction between the tropics and higher latitudes, 5) interannual variations in the tropics, 6) tropical clouds (including cloud physics, numerical simulations, etc.), 7) numerical weather prediction in lower latitudes, 8) weather forecasting in the tropics and socio-economic factors, and 9) methods of observation in the tropics.

The deadline for titles and abstracts has passed. Direct inquiries to: Dr. A. Katayama, Chairman, Program Committee of Regional Scientific Conference on Tropical Meteorology, Meteorological Society of Japan, c/o Japan Meteorological Agency, 3-4, Ote-Machi 1 Chome, Chiyoda-ku, Tokyo 100, Japan.

Extended abstracts will be published by WMO as one of the series of "Tropical Meteorological Research Program."

EWING SYMPOSIUM ON CLIMATE PROCESSES. SENSITIVITY TO SOLAR IRRADIANCE AND $\mathrm{CO}_{2}$, OCTOBER 25-27, 1982, PALISADES, N.Y.

The fourth biennial Ewing Symposium will be held 25-27 October 1982 at the Lamont-Doherty Geological Observatory in Palisades, N.Y. AMS is a cosponsor. The subject will be "Climate Processes: Sensitivity to Solar Irradiance and $\mathrm{CO}_{2}$." The focus will be on expected climate sensitivity for time scales from decades to the Milankovitch problem.

The invited contributions will allow consideration of specific aspects in the process areas (e.g., snow cover, sea ice, and ice sheets in the cryosphere) and expression of a range of opinion regarding sensitivity. The review papers and most of the shorter contributions have been selected, but suggested contributions central to the theme of the symposium will be considered at any time.

Inquiries regarding the scientific program should be directed to: James Hansen, Goddard Institute for Space Studies, 2880 Broadway, New York, N.Y. 10025 (tel: 212-678-5619); and inquiries on local arrangements should be directed to: Taro Takahashi, Lamont-Doherty Geological Observatory, Palisades, N.Y. 10964.

CONFERENCE ON CLOUD PHYSICS, NOVEMBER 15-18, 1982, CHICAGO, ILL.

The next national Conference on Cloud Physics, sponsored by the American Meteorological Society, will be held 15-18 November 1982 at the Americana Congress Hotel (a downtown "Loop" hotel) in Chicago, III. The purpose of the conference is to provide a forum for papers and discussions in all areas of cloud microphysics and cloud dynamics, including effects of radiation and electrical processes on cloud properties.

The deadline for titles and abstracts has passed. Direct inquiries to: Prof. Ramesh Srivastava, Dept. of Geophysical Sciences, 5734 S. Ellis Ave., Chicago, III. 60637 (tel: 312-753-8101).

The program was published in the June BULLETIN.

\section{FOURTH CONFERENCE ON PRECIPITATION} SCAVENGING, DRY DEPOSITION, AND RESUSPENSION, NOVEMBER 29-DECEMBER 3, 1982, LOS ANGELES, CALIF.

Previous conferences in this series were those held in Richland, Wash., and Champaign, Ill. This fourth conference will be held 29 November-3 December 1982 at the Sheraton Miramar Hotel in Santa Monica, Calif. The local host is the National Center for Intermedia Transport Research. Sponsors of the conference include the American Meteorological Society, the U.S. Department of Energy, and the U.S. Environmental Protection Agency. Honorary Chairman for the meeting will be Dr. A. C. Chamberlain, AERE Harwell, who will present the opening keynote address.

Papers encouraged were those that contribute to increased understanding, improved measurement methods, and new results for: collection efficiencies, scavenging rates and ratios, dry deposition fluxes and mechanisms, and resuspension rates and modes. Thus, it is not intended that this will be another "interdisciplinary, acid rain meeting," papers describing monitoring and numerical computations will be accepted only if scientific advances are emphasized, and time will not be available to discuss health and ecological effects, or legal and political ramifications. Especially encouraged were papers dealing with snow scavenging, aqueous-phase nitrogen chemistry, scavenging by (stratiform) low-precipitation-intensity clouds, particlesize-specific measurements of submicron-particle dry deposition, air/surface exchange of organic compounds, experimental and especially theoretical results in resuspension, and (most certainly) meso- and larger-scale meteorologic aspects of removal and resuspension (scavenging field studies, precipitation efficiency, and meteorologic aspects of dry deposition, deep mixing, and long-range transport).

The deadline for abstracts has passed, and authors invited to present papers have been notified. Direct inquiries to: Dr. W. George N. Slinn, Battelle Pacific Northwest Labs., P.O. Box 999, Richland, Wash. 99352 (tel: 509-375-4150 or 6161). The following schedule is planned authors should submit rough drafts of their papers by 1 November to their session chairman and to the Conference Secretary; a final, camera-ready draft of the papers will be due at the time of the conference registration.

Paper selection will be made by the Conference Co-Chairmen (Hans R. Pruppacher, Richard G. Semonin, and W. George N. Slinn), in consultation with appropriate members of the steering committee/session chairmen: $P$. Buat-Menard, J. A. Garland, D. F. Gatz, H. W. Georgii, D. 
A. Gillette, B. B. Hicks, H. Rodhe, G. A. Sehmel, P. W. Summers, and O. Vittori.

For further information about this meeting, please contact the Conference Secretary: V. B. McDonald, National Center for Intermedia Transport Research, 5531 Boelter Hall, Univ. of California, 405 Hilgard Ave., Los Angeles, Calif. 90024 (tel: 213-825-9741).

INTERNATIONAL SYMPOSIUM ON MILANKOVITCH AND CLIMATE: UNDERSTANDING THE RESPONSE TO ORBITAL FORCING, DECEMBER 1-3, 1982, PALISADES, N.Y.

The International Symposium on Milankovitch and Climate: Understanding the Response to Orbital Forcing will be held 1-3 December 1982 at the Lamont-Doherty Geological Observatory of Columbia University in Palisades, N.Y. The symposium is sponsored by the International Commission on Climate (ICCL) of the International Association of Meteorology and Atmospheric Physics (IAMAP), the Paleoclimatic Commission of INQUA, and the American Meteorological Society.

This symposium is being held to evaluate progress in understanding and modeling the mechanisms by which the climate system responds to orbital variation. The program will be organized to reflect both the recent rapid progress in numerical climate modeling and the mounting geological evidence in support of the astronomical theory.

Proposed sessions will examine 1) Orbital variations and their impact on the insolation regime, 2) Numerical modeling of the climatic response to orbital forcing, 3) Geological record of climate in the context of the astronomical theory, and 4) Recommendations for future research (final workshop).

The Symposium Co-Chairmen are John Imbrie, Dept. of Geological Sciences, Providence, R.I.; and Andre Berger, Univ. Catholique de Louvain, Louvain-la-Neuve, Belgium.

The deadline for abstracts has passed. Direct inquiries to Rose Marie Cline, Symposium Coordinator, LamontDoherty Geological Observatory, Palisades, N.Y. 10964.

Support is being sought for publication of a symposium volume.

SECOND CONFERENCE ON CLIMATE VARIATIONS, JANUARY 10-14, 1983, NEW ORLEANS, LA.

The Second Conference on Climate Variations, sponsored by the American Meteorological Society, will be held 10-14 January 1983, in conjunction with the 63rd AMS Annual Meeting (also 10-14 January) and the Conference on Climate/Energy Interactions (10-12 January), at the Sheraton New Orleans Hotel in New Orleans, La.

The principal emphases will be on: 1) large-scale regional and global climate variations extending over monthly though paleoclimatic time scales; 2) climate modeling, prediction, and sensitivity studies; and 3) man's impact on climate. The organizers would like to arrange a special session on large-scale atmospheric-oceanic features such as the Southern Oscillation, and changes in tropical and mid-latitude sea surface temperature anomalies and their role in climate forecasting.

The deadline for titles and abstracts has passed. Direct inquiries to Dr. Robert P. Harnack, Dept. of Meteorology \& Physical Oceanography, Rutgers Univ., P.O. Box 231, New Brunswick, N.J. 08903 (tel: 932-9520/9027/9387).

Hotel. All sessions will be held at the Sheraton New orleans Hotel. A block of rooms has been set aside for the meetings at the following special rates $\$ 48$, single; $\$ 62$, double; \$205, \$225, and \$360, one-bedroom suite; \$307, two-bedroom suite (these rates are subject to both state and local taxes which presently are $10 \%$ and subject to change without notice). The Sheraton New Orleans Hotel requires a deposit to hold all reservations. The deposit is to be equal to one night's stay. Personal check, money order, or a valid American Express card number and expiration date are acceptable. Kindly make your reservations prior to 3 December 1982 by writing directly to: Sheraton New Orleans Hotel, 500 Canal St., New Orleans, La. 70130 (teb 504-525-2500). Be sure to mention the American Meteorological Society's name when making reservations. For your convenience in securing accommodations, hotel reservation cards are available from AMS headquarters.

CONFERENCE ON CLIMATE/ENERGY INTERACTIONS, JANUARY 11-13, 1983, NEW ORLEANS, LA.

A Conference on Climate/Energy Interactions will be held 11-13 January 1983, in conjunction with the 63rd AMS Annual Meeting and the Second Conference on Climate Variations (10-14 January), at the Sheraton New Orleans Hotel in New Orleans, La. This conference is sponsored by the American Meteorological Society and cosponsored by the U.S. Department of Energy. The AMS Committee on Applied Climatology is cooperating.

The conference will devote its attention to the following three areas: 1) the atmospheric consequences of energy production from fossil fuels with emphasis on acid rain and potential climatic changes due to carbon dioxide; 2) the use of climate information for nuclear and the renewable energy sources such as solar, wind, biomass, or tidal; and 3) climate services for energy production distribution and estimation of fuel demands. Included in this area is the support of climatic information to production activities such as mining, exploration, and offshore oil production, and support to energy distribution activities such as planning of reserves and networks, and the use of climate information and forecasts in support of allocation decisions. The use of climate data and forecasts for estimating fuel demand is also included in this category.

One of the aims of this conference is to bring together members of the energy industry and the climate community to exchange information with the objective of improving the services provided by the climatologists to the energy industry.

The deadline for titles and abstracts has passed. Direct inquiries to the Program Chairman: Dr. John S. Perry, National Academy of Sciences, Climate Board, JH 404, 2101 Constitution Ave., N.W., Washington, D.C. 20418 (tel: 202-334-3517).

For details on securing accommodations, see "Hotel" paragraph above.

TOPICAL MEETING ON METEOROLOGICAL OPTICS, JANUARY 12-14, 1983, LAKE TAHOE/INCLINE VILLAGE, NEV.

A Topical Meeting on Meteorological Optics, sponsored by the Optical Society of America, will be held 12-14 January 1983 at the Hyatt Lake Tahoe in Incline Village, Nev. The American Meteorological Society is a cooperating society.

The deadline for abstracts has passed. Direct inquiries to the Chairman of the Technical Program Committee Dr. Bill Mach, 404 Love, Dept. of Meteorology, Florida State Univ., Tallahassee, Fla. 32306 (tel: 904-644-2752).

MIT JULE CHARNEY CELEBRATION, MARCH 21, 1983, CAMBRIDGE, MASS.

A symposium celebrating Jule Charney's contributions to atmospheric and oceanic science will be held at the Massachusetts Institute of Technology (MIT) on Monday, 21 March 1983, in Cambridge, Mass., sponsored jointly by MIT and AMS. Invited speakers will discuss major areas of Jule Charney's influence and his own views of meteorology, from the 1940s to the present time. The facilities at MIT are limited and admission will be on a first come, first served basis. Those who wish to attend should register as soon as possible with Mrs. Jane McNabb, Administrative Officer, 
Dept. of Meteorology, Massachusetts Institute of Technology, 54-1712, Cambridge, Mass. 02139 (tel: 617-253-2281).

SIXTH SYMPOSIUM ON TURBULENCE AND DIFFUSION, MARCH 22-25, 1983, BOSTON, MASS.

The Sixth Symposium on Turbulence and Diffusion, sponsored by the American Meteorological Society, will be held 22-25 March 1983 in conjunction with the Fourth Conference on Atmospheric and Oceanic Waves and Stability and the Fourth Conference on the Meteorology of the Upper Atmosphere at the 57 Park Plaza Howard Johnson's Motor Lodge in Boston, Mass. The symposium is cosponsored by the AMS Committees on Atmospheric Turbulence and Diffusion and Meteorological Aspects of Air Pollution.

Papers were solicited on fundamental aspects of 1) interaction of waves and turbulence--observational and theoretical studies; 2) theory and modeling of planetary boundary layers; 3) measurement techniques and experimental studies of PBL; 4) modeling turbulence and diffusion; 5) diffusion experiments and model validation studies; 6) parameterization of turbulence and diffusion in large-scale atmospheric circulation and transport models; 7) atmospheric flows and dispersion in nonhomogeneous (complex) terrain; and 8) other fundamental studies in turbulence and diffusion. Comprehensive review papers in the above-mentioned areas were also encouraged. The symposium format will consist largely of submitted papers with a few invited papers and panel discussions. Eight or nine regular half-day meeting sessions and, if needed, additional poster sessions are planned. One or more joint sessions are anticipated with the Fourth Conference on Atmospheric and Oceanic Waves and Stability and the Fourth Conference on the Meteorology of the Upper Atmosphere.

The deadline for titles and abstracts has passed. Direct inquiries to the Program Co-Chairman Dr. S. P. S. Arya, Dept. of Marine, Earth and Atmospheric Sciences, North Carolina State Univ., P.O. Box 5068, Raleigh, N.C. 27650 (tel: 919-737-3717). Authors will be notified by 30 September 1982 regarding acceptance of their papers.

Instructions and special typing paper will be furnished by AMS to authors of accepted papers. A complete camera-ready extended abstract of no more than 4 pages, including diagrams, must be received at AMS headquarters no later than 15 November 1982. Page charges will be assessed to help defray printing costs. A preprint volume of extended abstracts will be prepared and distributed to preregistrants (in U.S. and Canada) before the meeting. Other symposium participants will receive the preprint volume at the time of registration.

\section{Call for Papers}

FOURTH CONFERENCE ON ATMOSPHERIC AND OCEANIC WAVES AND STABILITY, MARCH 22-25, 1983, BOSTON, MASS.

The Fourth Conference on Atmospheric and Oceanic Waves and Stability, sponsored by the American Meteorological Society, will be held 22-25 March 1983 in conjunction with the Sixth Symposium on Turbulence and Diffusion and the Fourth Conference on the Meteorology of the Upper Atmosphere at the 57 Park Plaza Howard Johnson's Motor Lodge in Boston, Mass. Like its predecessors, this conference is intended to provide a forum for exposition and discussion of the dynamics of waves and wave-like flows in oceans and atmospheres. The atmosphere and the oceans are active fluids, but at many times and in most environments, they are dynamically stable, which implies that forcing disturbances produce some form of propagating waves. Thus wave dynamics is a common foundation to all geophysical fluids, and many techniques of wave analysis pass readily across the air-sea interface. The conference is dedicated to the memory of Prof. Jule Charney, who contributed immensely to the advancement of our field and to previous waves and stability conferences. A special memorial session for Prof. Charney will be held 21 March on the campus of the Massachusetts Institute of Technology.

Papers are solicited in observational, theoretical, and experimental areas, with a preference for work related to Charney's interests and contributions. One or more joint sessions are anticipated with the Sixth Symposium on Turbulence and Diffusion and the Four th Conference on the Meteorology of the Upper Atmosphere.

Titles and abstracts of about 100 words should be submitted by 1 October 1982 to the Program Chairman: Dr. D. K. Lilly, NCAR, P.O. Box 3000, Boulder, Colo. 80307 (tel: 303-497-0633). Before submitting abstracts, see "New Meeting Procedures for Authors" following the list of meetings at the beginning of this section. It is anticipated that over 100 papers will be presented. The Program Committee must, however, exercise the right to reject papers that appear irrelevant, unsound, duplicative, or uninformative. In order to allow the committee to function efficiently and fairly, authors are urged to prepare articulate and succinct abstracts. At their option, authors may also send a more extensive summary, including a key figure or two. In addition, student and junior authors may choose to include, or have sent separately, a reference letter from a professor or senior colleague. Review papers of substantial scope and breadth are also solicited, for which it is requested that the author provide an outline of the subject area to be reviewed.

In order to allow the most efficient and direct communication between authors and audience and to avoid multiple and evening sessions, an emphasis on poster presentations is planned. It is anticipated that most sessions will include one or two comprehensive review papers, given orally, with the bulk of the contributions delivered in the poster format. An open discussion period will follow each poster session, and authors will be encouraged to leave their posters on display for at least a full day. Instructions and recommendations on effective use of the poster format will be sent to authors of accepted papers.

\section{Call for Papers}

FOURTH CONFERENCE ON THE METEOROLOGY OF THE UPPER ATMOSPHERE, MARCH 22-25, 1983, BOSTON, MASS.

The Fourth Conference on the Meteorology of the Upper Atmosphere, sponsored by the American Meteorological Society and organized by the AMS Committee on the Upper Atmosphere, will be held 22-25 March 1983 in conjunction with the Sixth Symposium on Turbulence and Diffusion and the Fourth Conference on Atmospheric and Oceanic Waves and Stability at the 57 Park Plaza Howard Johnson's Motor Lodge in Boston, Mass. One or more joint sessions are planned with these other two meetings.

Contributed papers on significant new observational and theoretical results are solicited. Invited review papers will be presented to cover the spectrum of upper atmosphere research problems. Topics on the upper atmosphere that will be emphasized include: 1) wave phenomena and their effects; 2) turbulence and diffusion; 3) analysis of observations of meteorological variables and constituents; 4) interaction of dynamics, radiation, and chemistry; 5) general circulation, and 6) transport of minor constituents.

Abstracts (about 100 words) of contributed papers, suitable for selection and program organizational purposes, should be sent by 1 October 1982 to the Program Chairman: Dr. Darrell F. Strobel, Code 4780, Naval Research Lab., Washington, D.C. 20375 (tel: 202-767-3037). Authors will be notified regarding acceptance by 1 December 1982. For those authors whose work has progressed sufficiently to write an informative abstract, it is requested that a final abstract be submitted 
by 1 January 1983. Before submitting abstracts, see "New Meeting Procedures for Authors" following the list of meetings at the beginning of this section.

\section{Call for Papers}

FIFTH SYMPOSIUM ON METEOROLOGICAL OBSERVATIONS AND INSTRUMENTATION, APRIL 11-15, 1983, TORONTO, ONT., CANADA

The Fifth Symposium on Meteorological Observations and Instrumention, sponsored by the American Meteorological Society and the Canadian Meteorological and Oceanographic Society, will be held 11-15 April 1983 at the Loews Westbury Hotel in Toronto, Ont., Canada. The AMS Committee on Atmospheric Measurements will organize the technical program through a local program committee. The Toronto Chapter of the CMOS and the Atmospheric Environment Service of the Government of Canada will be the local hosts. Every effort will be made to make everyone thoroughly at home in downtown Toronto.

The purpose of the symposium is to provide a unique opportunity for wide-ranging communication, both in formal single sessions and in impromptu gatherings. Let us know your wishes. It is emphasized that the symposium covers meteorological observations as well as instrumention, and is where fundamental questions of data needs and representativeness, and maintenance of accuracy in operational networks, share equally with complex data processing, with modeling techniques, and with the new technologies. Papers are solicited on this full range of subjects. Pesentation time will be limited to a maximum of 20 minutes per paper.

An exhibit of meteorological sensors and equipment is being considered. Prospective exhibitors should contact AMS headquarters.

Submit 100-word abstracts with your name and complete mailing address by 15 September 1982 to the Symposium Chairmans William L. Clink, Atmospheric Environment Service/ACSL, 4905 Dufferin St., Downsview, Ont., Canada M3H 5T4 (tek 416-667-4650). Before submitting abstracts, see "New Meeting Procedures for Authors" following list of meetings at the beginning of this section.

Complete camera-ready manuscripts of no more than 8 pages must be received at AMS headquarters by $\underline{2}$ December 1982. Instructions and special typing paper will be furnished to authors of accepted papers. Page charges will be assessed to defray the cost of printing. A preprint volume will be distributed only to preregistrants (in U.S. and Canada) before the meeting. Other participants will receive the preprint volume at the time of registration.

\section{Call for Papers}

16TH CONFERENCE ON AGRICULTURE AND FOREST METEOROLOGY, A PRIL 25-29, 1983, FT. COLLINS, COLO.

The 16th Conference on Agriculture and Forest Meteorology, sponsored by the American Meteorological Society, will be held 25-29 April 1983 in Ft. Collins, Colo. The conference will be held concurrently with the Sixth Conference on Biometeorology and Aerobiology and the Seventh Conference on Fire and Forest Meteorology.

The focus of the conference will be on "Application of Meteorological Information to Meet Problems in Agriculture and Forestry." The program will include general sessions on 1) Microclimate of crop canopies, 2) Forest meteorology, 3) New developments in instruments for meteorological measurements, and 4) Application of meteorological information to agriculture and forestry. Joint sessions with the Sixth Conference on Biometeorology and Aerobiology will include pest-weather and animal-weather interactions, joint sessions with the AMS Committee on Climate Variations and the Sixth Conference on Biometeorology and Aerobiology will include the impacts of climate change on the biological environment, and a joint session with the Seventh Conference on Fire and Forest Meteorology will include canopy turbulence modeling.

Titles and short abstracts (200-300 words), typed double-spaced, should be sent no later than 5 October 1982 to Dr. William A. Dugas, Blackland Research Center, P.O. Box 748, Temple, Tex. 76503 (tel: 817-774-1201). All abstracts will be reviewed for their applicability to the program and session theme. Concurrent sessions with the Sixth Conference on Biometeorology and Aerobiology and Seventh Conference on Fire and Forest Meteorology are planned. However, the number of spaces available for papers is limited and if the number of papers exceeds the allotted time, papers that present original and new concepts and adhere to the program will be selected.

Instructions and special typing paper will be furnished to the authors of accepted papers. A complete camera-ready manuscript of no more than 4 pages, including diagrams, must be received at AMS headquarters no later than $\underline{6}$ December 1982. Page charges will be assessed to help defray printing costs. A preprint volume of extended abstracts will be prepared and distributed only to preregistrants (in U.S. and Canada) before the meeting. Other conference participants will receive the preprint volume at the time of registration.

\section{Call for Papers}

SIXTH CONFERENCE ON BIOMETEOROLOGY AND AEROBIOLOGY, A PRIL 25-29, 1983, FT. COLLINS, COLO.

The Sixth Conference on Biometeorology and Aerobiology, sponsored by the American Meteorological Society, will be held 25-29 April 1983 in Ft. Collins, Colo. Members of the American Institute of Medical Climatology have also been invited to attend. The conference will be held concurrently with the 16th Conference on Agriculture and Forest Meteorology and the Seventh Conference on Fire and Forest Meteorology. Joint sessions are planned with all three groups.

The conference will include sessions on aerobiology, the effects of weather and climate (including the impact of past and future climatic variation) on plants and animals (organized by the AMS Committee on Climate Variations), human and urban biometeorology, and physiological ecology. Interdiscipl inary papers suitable for joint sessions, dealing with the effects of fluctuating climate on plants and animals or with biological indicators of climate variations, are especially encouraged.

Titles and short abstracts (200-300 words), typed double-spaced, should be sent no later than 5 October 1982 to Dr. Dennis M. Driscoll, Dept. of Meteorology, Texas A\&M Univ., College Station, Tex. 77843 (te上 713-845-5632). Before submitting abstracts, see "New Meeting Procedures for Authors" following the list of meetings at the beginning of this section.

Instructions and special typing paper will be furnished to the authors of accepted papers. A complete camera-ready manuscript of no more than 4 pages, including diagrams, must be received at AMS headquarters no later than 6 December 1982. Page charges will be assessed to help defray printing costs. A preprint volume of extended abstracts will be prepared and distributed only to preregistrants (in U.S. and Canada) before the meeting. Other conference participants will receive the preprint volume at the time of registration.

\section{Call for Papers}

SEVENTH CONFERENCE ON FIRE AND FOREST METEOROLOGY, A PRIL 25-29, 1983, FT. COLLINS, COLO.

The Seventh Conference on Fire and Forest Meteorology, sponsored by the American Meteorological Society and the Society of American Foresters, will be held 25-29 April 1983 in Ft. Collins, Colo. The conference will be held concurrently with the 16 th Conference on Agriculture and 
Forest Meteorology and the Sixth Conference on Biometeorology and Aerobiology. Joint sessions are planned with all three groups.

The program will consist of invited and contributed papers. Suggested topics are fire weather, wilderness fires, prescribed fires, smoke management, numerical modeling of forest fires, probability modeling of forest fires, laboratory simulation of forest fires, plume rise, plume diffusion and dispersion, forest canopy air flow, turbulence in flow above a forest canopy, numerical modeling of canopy flow, wind tunnel modeling of canopy flow, measurement of forest fire parameters, and measurement of meteorological parameters in a forest environment. Papers of fundamental, applied, and operational nature and papers exploring the impact of basic and applied research upon the operational problems that forest managers face are sought.

Extended abstracts (up to 1000 words) are to be submitted by 1 October 1982 to 1) Program Chairman, Dr. Willy Z. Sadeh, Professor of Engineering and Fluid Mechanics, Dept. of Civil Engineering, Colorado State Univ., Ft. Collins, Colo. 80523 (tel: 303-491-8573); and/or 2) Program Co-Chairman, Dr. William R. Furman, Research Meteorologist, Rocky Mt. Forest \& Range Experiment Station, USDA Forest Service, 240 W. Prospect St., Ft. Collins, Colo. 80526 (teb 303-221-4390). Before submitting abstracts, see "New Meeting Procedures for Authors" following the list of meetings at the beginning of this section.

Instructions and special typing paper will be furnished to the authors of accepted papers. A complete camera-ready manuscript of no more than 8 pages, including figures and tables, must be received at AMS headquarters no later than 6 December 1982. Page charges will be assessed to help defray printing costs. A preprint volume will be prepared and distributed only to preregistrants (in U.S. and Canada) before the meeting. Other conference participants will receive the preprint volume at the time of registration.

\section{Call for Papers}

FIRST CONFERENCE ON MESOSCALE METEOROLOGY, MAY 31-JUNE 3, 1983, NORMAN, OKLA.

The First Conference on Mesoscale Meteorology, cosponsored by the American Meteorological Society and the Cooperative Institute for Mesoscale Meteorology Studies (CIMMS), will be held 31 May-3 June 1983 on the campus of the University of Oklahoma in Norman, Okla. This is the first of what will likely become a regular series of such meetings.

It is the intention of the conference organizers to bring together scientists involved in basic studies of a wide range of atmospheric circulation systems that occur on the mesoscale, which for the purposes of this conference is taken to include only those circulation systems that are large enough to be essentially hydrostatic, but too small to be describable in a quasi-geostrophic context. Examples of specific subjects appropriate to the conference include frontal circulations, hydrostatic ageostrophic flow over orography, diurnal circulations, organization of convection on scales fundamentally larger than that of the cumulus cloud, and hydrostatic inertia-gravity waves and related phenomena. Peference will be given to papers that demonstrate fundamental breakthroughs in understanding of physical processes. Examples of subjects that will not be considered appropriate include the physics and dynamics of processes operative on the cumulus cloud scale, studies dealing primarily with technology development and data collection, and investigations concerning the impact of weather on man; these should be submitted for consideration to other specialized symposia.

The 4-day conference will host about 50 invited and contributed presentations, each of which will be at least 15 minutes in length with an additional 10 minutes for questions and discussion. Those interested in contributing to the conference should submit a title and brief (less than
150 words) abstract together with a reviewer's abstract long enough to describe the essential nature and results of the work (but not longer than 600 words) not later than 1 December 1982 to: Dr. Kerry A. Emanuel, Dept. of Meteorology and Physical Oceanography, Massachusetts Institute of Technology, Room 54-1616, Cambridge, Mass. 02139 (tel: 617-253-2462). Students are encouraged to submit abstracts; each student should also send a letter from his or her adviser explaining the significance of the work. Before submitting abstracts, see "New Meeting Procedures for Authors" following the list of meetings at the beginning of this section.

Further inquiries should be addressed to Dr. Emanuel at the address above, or to: Dr. Richard Carbone, NCAR, P.O. Box 3000, Boulder, Colo. 80307 (tel: 303-497-0648).

\section{Call for Papers}

SIXTH CONFERENCE ON NUMERICAL WEATHER PREDICTION, JUNE 6-9, 1983, OMAHA, NEBR.

The Sixth Conference on Numerical Weather Prediction (NW P), sponsored by the American Meteorological Society, will be held 6-9 June 1983 at the Red Lion Inn in Omaha, Nebr. This conference will be held concurrently with the Ninth Conference on Aerospace and Aeronautical Meteorology and one or two joint sessions are planned. The AMS Omaha-Offutt Chapter will serve as local host.

The theme of the conference will be to consider the problems in numerical weather prediction and analysis. Papers are particularly solicited in the following areas 1) Limited-area and mesoscale modeling with application to improving short-term weather forecasting; 2) Global-scale modeling; 3) Operational numerical modeling; 4) Numerical analysis and initialization techniques; 5) Impact of data sources on numerical weather analysis and prediction; 6) Operational uses of, and problems with, NW P products; 7) Verification methods for NWP products; 8) Research numerical modeling; and 9) Physical modeling and parameterization.

Titles and abstracts (200-400 words), typed double-spaced, must be submitted by 1 November 1982 to the Program Chairman: Lt. Col. James Kerlin, Air Force Global Weather Central (AFGWC)/WF, Offutt AFB, Nebr. 68113 (tel: 402-294-2192). Please include with each submission a complete mailing address and telephone number to facilitate communication. Also include the official author's name, organization, and location as desired for the BULLETIN program. Authors will be notified on or about 15 January 1983 regarding the acceptance of papers. Before submitting abstracts, see "New Meeting Procedures for Authors" following the list of meetings at the beginning of this section.

A preprint volume of papers is anticipated. Instructions and special typing paper will be furnished to the authors of accepted papers. A complete camera-ready manuscript of no more than 8 pages in length, including diagrams and photographs, must be received at AMS headquarters no later than 1 March 1983. Page charges will be assessed to help defray the printing costs. A preprint volume will be prepared and distributed only to preregistrants prior to the meeting. Other conference participants will receive the preprint volume at the time of registration.

\section{Call for Papers}

NINTH CONFERENCE ON AEROSPACE AND AERONAUTICAL METEOROLOGY, JUNE 6-9, 1983, OMAHA, NEBR.

The Ninth Conference on Aerospace and Aeronautical Meteorology, sponsored by the American Meteorological Society with the cooperation of the American Institute of Aeronautics and Astronautics and the National Weather Association, will be held 6-9 June 1983 at the Red Lion Inn 
in Omaha, Nebr. This conference will be held concurrently with the Sixth Conference on Numerical Weather Prediction and one or two joint sessions are planned. The technical program is being arranged by the AMS Committees on Meteorological Aspects of Aerospace Systems (COMAAS) and Aviation Meteorology (CAMET), the National Weather Association (NWA), and the AIAA Technical Committee on Atmospheric Environment. The AMS Omaha-Offutt Chapter will serve as local host.

The theme of the conference will be meteorology related to engineering design, operation, and safety for current and future technological systems and methods of information retrieval. Contributed papers in the following areas are welcomed information retrieval--contents and methods of accessing repositories of meteorological data, weather information retrieval systems (interactive display systems), data sets available from large federal experimental field programs; electro-optics meteorology (visible to near millimeter)--modeling and measurement of natural optical contaminants, sources and dispersal of obscurants, effects of upper atmospheric electricity and chemistry on surveillance and communication systems, boundary layer and air-sea interaction effects; range meteorology--precipitation, dust, snow, fog, electric fields, etc.; Space Shuttle and ballistic missiles--forecasting for launch and landing, plume dispersion, contamination and a ir quality control, orbital and upper atmospheric environment for aerospace vehicle design and operations; aviation weather--short-term aviation forecasting, dissemination of critical weather, pilot weather briefing and training, automated weather monitoring and reporting systems, terminal and en route hazardous weather, meteorological aspects of fuel economy; satellite- and ground-based sensors and data processing--aerosols, temperature, liquid water content, etc., laser acoustic and radar Doppler systems, atmospheric electricity and lightning detection sensors and data processing.

Titles and abstracts (200 words), typed double-spaced, should be sent no later than $\perp$ November 1982 to the General Chairman: Mr. R. Craig Goff, ACT-250, FAA Technical Center, Atlantic City, N.J. 08405 (tel: 609-641-8200, ext. 2130 or 2522; FTS: 346-2130). Each abstract should contain the author's name(s), complete mailing address, and telephone number. Before submitting abstracts, see "New Meeting Procedures for Authors" following the list of meetings at the beginning of this section.

A preprint volume of papers is planned. Instructions and special typing paper will be furnished to the authors of accepted papers. A complete camera-ready manuscript of no more than 6 pages in length, including diagrams and photographs, must be received at AMS headquarters no later than I March 1983. Page charges will be assessed to help defray printing costs. A preprint volume will be prepared and distributed only to preregistrants prior to the meeting. Other conference participants will receive the preprint volume at the time of registration.

The Technical Chairman is Dr. Walter Frost, University of Tennessee Space Institute, Tullahoma, Tenn. Other members of the Conference Planning Committee are: William Vaughan, Sol Hirsh, Eric Mandel, Billy McCormac, James Kerlin, Tom Pries, and Roland Nagle.

\section{Call for Papers}

INTERNATIONAL SYMPOSIUM ON GAS TRANSFER AT WATER SURFACES, JUNE 13-15, 1983, ITHACA, N.Y.

An International Symposium on Gas Transfer at Water Surfaces will be held 13-15 June 1983 at Cornell University in Ithaca, N.Y. The symposium is cosponsored by the American Chemical Society, American Geophysical Union, American Meteorological Society, American Society of Civil Engineers, International Association for Hydraulic Research, U.S. Environmental Protection Agency, U.S. National Science Foundation, and World Meteorological Organization.
The purpose of the symposium is to summarize the state of the art and to further scientific understanding of gas transfer processes at the air-water interface of environmental water bodies. The symposium program will cover the following topics: 1) Physico-chemical phenomena and molecular properties of the air-water interface; 2) Turbulence near gas-liquid interfaces including bottom shear, wind shear, and convective turbulence generation; 3) predictive models of the exchange process; 4) laboratory and field measurement techniques, and 5) application to environmental problem areas including reaeration, volatilization of toxics, climate factors, etc., ranging from inland water bodies to estuaries and the ocean.

The deadline for abstracts (200-400 words) is 31 October 1982. Authors will be notified of acceptance by 15 December 1982, and final manuscripts will be due on 31 March 1983. In addition to regular papers, several invited keynote papers will survey the symposium topics as outlined above. All accepted papers will be published in book form.

The Scientific Advisory Committee consists of: S. A. Kitaigorodskii, Johns Hopkins Univ.; J. L. Lumley, Cornell Univ.; D. Mackay, Univ. of Toronto; K. O. Munnich, Univ. of Heidelberg; D. J. O'Connor, Manhattan College; and N. Yotsukura, U.S. Geological Survey.

Send paper abstracts and requests for fur ther information to the Co-convenors: W. H. Brutsaert or G. H. Jirka, School of Civil and Environmental Engineering, Cornell Univ., Ithaca, N.Y. 14853 (tel: $607-256-3676$ or 5140 ).

\section{Call for Papers}

JOINT ANNUAL MEETINGS OF AAAS (PACIFIC DIVISION) AND AAAS (SOUTHWESTERN AND ROCKY MOUNTAIN DIVISION), JUNE 19-24, 1983, LOGAN, UTAH

The 64th Annual Meeting of the American Association for the Advancement of Science (Pacific Division) and the 59 th Annual Meeting of the AAAS (Southwestern and Rocky Mountain Division) will be held jointly, 19-24 June 1983, at Utah State University in Logan, Utah.

The American Meteorological Society and Section W (Atmospheric and Hydrospheric Sciences) of the two divisions of AAAS will cosponsor paper sessions, a symposium, and other programs. Atmospheric energy, environmental pollution, and the climatology, meteorology, and hydrography of arid and semi-arid areas are among the topics expected to be investigated.

Abstracts of papers should be typed on 8-1/2" X 11 " white bond paper. Title and text of abstract should be camera-ready without paragraphs and should fit inside a 5" square box, with a 1" margin to the left of the box. Special symbols and signs that must be hand-lettered should be rendered in reproducible black ink. Author's name, affiliation, and address should appear at the bottom of the page. Abstracts will be published in a proceedings for distribution to registrants. Each presentation will be allotted 20 minutes, including discussion.

Abstracts should be sent by 1 April 1983 to the Program Chairman: Dr. John Lier, Dept. of Geography and Environmental Studies, California State Univ., Hayward, Calif. 94542 (tel: 415-881-3193). The Program Chairman should be informed by the abstract deadline of any need for $35 \mathrm{~mm}$, lantern slide, opaque, or overhead projectors, or for special equipment.

Details on the entire program, registration, housing, and transportation can be obtained from: Dr. Alan E. Leviton, Executive Director, AAAS (Pacific Division), California Academy of Sciences, Golden Gate Park, San Francisco, Calif. 94118 (tel: 415-752-1554); or Dr. M. Michelle Balcomb, Executive Officer, AAAS (Southwestern and Rocky Mountain Division), Colorado Mountain College, 3000 Country Rd. 114, Glenwood Springs, Colo. 81601 (tel: 303-945-8165). Nonmembers of AAAS are encouraged to attend. 


\section{Call for Papers}

IGS SYMPOSIUM ON ICE AND CLIMATE MODELING, JUNE 27-JULY 1, 1983, EVANSTON, ILL.

A Symposium on Ice and Climate Modeling, sponsored by the International Glaciological Society, will be held 27 June-1 July 1983 at Northwestern University in Evanston, Ill. The American Meteorological Society will be a cosponsor.

The symposium will be concerned with the following topics 1) Ice data for the present climate--continental and marine ice sheets, sea ice, and snow cover; 2) Modeling of the present climate--atmospheric climate models (e.g., global climate models, energy balance models), oceanic climatic models, ice models, and coupled atmospheric, oceanic, and ice models; 3) Ice and climate data for the Pleistocene and the Holocene--reconstructions of the $18 \mathrm{k}$ bp climate and climate episodes in the Holocene and ice volume, ocean temperature time series reconstructions; and 4) Climate modeling of the Pleistocene and the Holocene--snapshot or episodic modeling (e.g., $18 \mathrm{k}$ bp or the Climate Optimum) and time series modeling of ice volume, temperature, etc.

The Papers Committee will be happy to consider any paper on the above topics. The number of papers accepted will be limited to allow ample time for interdisciplinary discussion of broad issues and future cooperative modeling. Details about the summaries and final papers will be given in the Second Circular, to be published in the summer of 1982. We have not been advised of deadlines; therefore, we suggest that you submit your summary as soon as possible to The Secretary-General, International Glaciological Society (IGS), Lensfield Rd., Cambridge, U.K. CB2 IER. The Papers Committee may decide to invite review papers on some of the topics if submitted contributions do not give sufficient coverage.

The proceedings of the symposium will be published by IGS as Volume 5 of the Annals of Glaciology. Papers will be refereed according to the Society's usual standards before being accepted for publication.

Requests for copies of the Second Circular containing information on accommodations, general program, and preparation of summaries and final papers should be directed to the IGS Secretary-General (see address above).

The Organizing Committee consists of: G. E. Birchfield, H. Richardson, S. Schneider, and J. Weertman.

\section{Call for Papers}

\section{FOURTH INTERNATIONAL CONFERENCE ON PERMAFROST, JULY 18-22, 1983, FAIRBANKS, ALASKA}

The Fourth International Conference on Permafrost, organized by the National Academy of Sciences and the state of Alaska, will be held 18-22 July 1983 at the University of Alaska in Fairbanks, Alaska. Cosponsors of some of the technical sessions are the American Society of Civil Engineers (Technical Council on Cold Regions Engineering), the American Society of Mechanical Engineers (Low Temperature Heat Transfer Committee), and the American Meteorological Society (Committee on Polar Meteorology).

The technical program will consist of two parts reviews of six themes identified as being particularly timely, and presentations of contributed papers. The reviews will be presented in the format of panel discussions among invited experts in each topic. The themes are as follows 1) Pipeline construction, 2) Climatic change and geothermal regime, 3) Deep foundations and embankments, 4) Permafrost terrain and environmental protection, 5) Frost heave and ice segregation, and 6) Subsea permafrost.

Contributed papers on all aspects of permafrost engineering and science are welcome. Extended abstracts will be due for review by 1 October 1982. Papers for conference presentation will be due on 1 March 1983 and will be reviewed prior to publication. Papers must be read in English and will be presented only if an author is present. Assistance in presentations will be provided if necessary. Further instructions for the submission of abstracts and papers will appear in future issues of the BULLETIN.

Displays of construction, transportation, and geophysical equipment and scientific exhibits are planned. Movies and slide presentations are welcome, as are institutional and agency displays. Interested persons should contact the Local Organizing Committee Fourth International Conference on Permafrost, Geophysical Institute, Univ. of Alaska, Fairbanks, Alaska 99701 (tel: 907-479-7371; Telex: 35414).

For further information regarding the technical program, registration, accommodations, and social events and field trips, contact the U.S. Organizing Committee Fourth International Conference on Permafrost, Polar Research Board, National Academy of Sciences, 2101 Constitution Ave., N.W., Washington, D.C. 20418 (tel: 202-389-6071; Telex: 248664).

Members of the U.S. Organizing Committee include: T. L. Pewe, Chairman; G. E. Weller, Vice-Chairman; and A. J. Alter, J. Barton, J. Brown, O. J. Ferrians, Jr., H. O. Jahns, J. R. Kiely, A. H. Lachenbruch, R. D. Miller, A. L. Washburn, J. H. Zumberge, and L. DeGoes, Executive Secretary.

\section{Call for Papers}

FIRST INTERNATIONAL CONFERENCE ON SOUTHERN HEMISPHERE METEOROLOGY, JULY 31-AUGUST 6, 1983, SAO JOSE DOS CAM POS, BRAZIL

The First International Conference on Southern Hemisphere Meteorology, sponsored by the American Meteorological Society, will be held in 31 July- 6 August 1983 in Sao Jose dos Campos, Brazil.

Papers are solicited on all aspects of Southern Hemisphere meteorology, but particular attention is focused on 1) Short- and medium-range weather forecasting and analyses of the Southern Hemisphere (predictability, special initialization procedures, verification problems, data requirements, etc.); 2) Observations, models, and theories of its general circulation (stationary wave phenomena, circulation differences, and similarities between hemispheres, role of Antarctic, impact of observational systems, etc.); 3) Interaction of the Northern and Southern Hemispheres and between tropical and extratropical latitudes (Southern Oscillation, QBO, South Pacific cloud band, etc.); and 4) Climatic variability with emphasis on seasonal and interannual time scales.

Three (3) copies of proposed titles, a short abstract $(100$ words), and a reviewer's abstract ( $1-4$ pages, including figures, if desired) should be submitted no later than 15 December 1982 to the Program Chairman: Prof. J. $\overline{\mathrm{N}}$. Paegle, Dept. of Meteorology, 819 W. C. Browning Bldg., Univ. of Utah, Salt Lake City, Utah 84112 (tel 801-581-6136). It is preferred that the abstracts be written in English, but those in Spanish will also be considered. Authors will be notified by mail about February 1983 as to receipt and acceptance of their abstracts. Please include complete mailing address and telephone number.

A preprint volume of extended abstracts (paper summaries) will be distributed at the time of the conference. Instructions and special typing paper will be furnished to authors of accepted papers. A complete camera-ready manuscript of no more than 4 pages in length, including diagrams and photographs, must be received at AMS headquarters no later than 2 May 1983.

The Program Committee consists of: J. N. Paegle, Chairman, and G. C. Cressman, D. J. Gauntlett, E. Kalnay, G. Necco, K. E. Trenberth, D. G. Vincent, and P. J. Webster.

AMS has applied for an NSF grant to provide travel for a limited number of U.S. scientists who are not employed by the government or by the government sponsored laboratories. Those eligible who intend to present a paper may contact AMS headquarters for applications and further information. 
SHORT COURSE ON INSTRUMENTS AND TECHNIQUES FOR PROBING THE ATMOSPHERIC BOUNDARY LAYER, AUGUST 1983, BOULDER, COLO.

A Short Course on Instruments and Techniques for Probing the Atmospheric Boundary Layer, sponsored by the American Meteorological Society, will be held in August 1983 in Boulder, Colo. The AMS Committees on Atmospheric Turbulence and Diffusion and Atmospheric Measurements are arranging for the program.

The purpose of the course is to present a current summary of instruments and techniques that are used to probe the atmospheric boundary layer. This includes both direct and remote sensing instrumentation, sampling strategies, error analysis, and computational techniques. The course should be useful for scientists, engineers, and graduate students who wish to become familiar with, or update their knowledge of observational techniques in the boundary layer. The course will concentrate on general principles of observational techniques and should be useful for both practically oriented experimenters and those interested in a general understanding of observational techniques in the boundary layer. Attention will also be given to recent developments that are experimental, but useful for research or have promise for eventual practical applications.

It is tentatively planned that the course will cover 5 days with about 8 half-day sessions of lectures and discussion and 2 half-days of tours and demonstrations of research capabilities in the Boulder area (possibly the NOAA Boulder Atmospheric Observatory and the NCAR Research Aviation Facility and Field Observing Facility). There will be $8-12$ guest lecturers, each of whom will also contribute to a monograph that will be available to participants in the course in the form of lecture notes, and subsequently will be published.

The Program Chairman is Dr. Donald H. Lenschow, NCAR, P.O. Box 3000, Boulder, Colo. 80307. As details develop, they will be published in future issues of the BULLETIN.

XVIII GENERAL ASSEMBLY OF THE IUGG, AUGUST 15-17, 1983, HAMBURG, F.R.G.

In response to an invitation from the National Committee for Geodesy and Geophysics of the Federal Republic of Germany, The International Union of Geodesy and Geophysics (IUGG) will hold its XVIII General Assembly in Hamburg, F.R.G., 15-27 August 1983.

To have your name placed on the mailing list to receive further details and information circulars, write directly to: Dr. W. Zahel, Chairman, Local Organizing Committee, IUGG 1983, Hamburg Messe und Congress GmbH - Congress Organization - Postfach 302360, 2000 Hamburg 36, Federal Republic of Germany.

Call for Papers

FIFTH INTERNATIONAL SYMPOSIUM OF THE IAMAP COMMISSION ON ATMOSPHERIC CHEMISTRY AND GLOBAL POLLUTION, AUGUST 29-SE PTEMBER 3, 1983, OXFORD, ENGLAND

The Fif th International Symposium of the IAMAP Commission on Atmospheric Chemistry and Global Pollution (CACG P) will be held 29 August-3 September 1983 at Christ Church College of Oxford University in Oxford, England. AMS is a cosponsor.

Emphasis will be on the regional and global tropospheric cycles of nitrogen and sulfur and the chemistry of clouds and precipitation. Relative to the global $\mathrm{S}$ and $\mathrm{N}$ cycles, contributed papers are solicited on the measurement of $S$ and $\mathbf{N}$ species in both the gas and aerosol phase in the regional and global troposphere; sources, sinks, and transformation processes of $\mathrm{S}$ and $\mathrm{N}$ species; the roles of heterogeneous processes in the $S$ and $N$ cycles; gas/particle conversion; and theoretical modeling of these substances.
Relative to precipitation and cloud chemistry, papers are solicited on concentrations and variability of trace substances on the regional and global scales; factors controlling the acidity of precipitation; in and below cloud scavenging processes (particularly of trace gas species); and the role of precipitation in global biogeochemical cycles. Both oral and poster presentations will be possible. Note that this symposium will take place the week following the 18th IUGG General Assembly in Hamburg, F.R.G.

Abstracts (in English) up to 300 words, single-spaced, should include the title, authors, and their affiliations and addresses. Two copies of each abstract should be submitted no later than 1 April 1983 as follows-From North American authors, to: Robert A. Duce, Secretary, CACG P, Center for Atmospheric Chemistry Studies, Graduate School of Oceanography, Box 3, Univ. of Rhode Island, Kingston, R.I. 02881; From all other authors, to Phil Goldsmith, Meteorological Office, London Rd., Bracknell, Berks., England RG12 2SZ. Papers will be selected for presentation at the symposium by the Program Committee on the basis of information contained in the abstracts.

Program Committee members include P. Goldsmith, R. Duce, P. Crutzen, D. Whelpdale, and H. Rodhe.

Papers presented at the meeting will be submitted for publication together in a refereed journal. Details will be announced at a later time.

\section{Call for Papers}

SYMPOSIUM ON MAINTENANCE OF THE QUASI-STATIONARY COMPONENTS OF THE FLOW IN THE ATMOSPHERE AND IN ATMOSPHERIC MODELS, AUGUST 30-SE PTEMBER 2, 1983, PARIS, FRANCE

A Symposium on Maintenance of the Quasi-Stationary Components of the Flow in the Atmosphere and in Atmospheric Models will be held 30 August-2 September 1983 in Paris, France. The symposium is sponsored by IAMAP and WMO. AMS is a cooperating society.

Recent work has drawn attention to the fact that errors in the treatment of the quasi-stationary component of the flow are important contributors to the forecast errors. There is also evidence that high-resolution general circulation models have important and related errors in the treatment of the quasi-stationary part of the flow.

This symposium will bring together workers on observational and theoretical aspects, along with general circulation modelers and numerical weather prediction specialists, to discuss the mechanisms that maintain the quasi-stationary part of the flow. Topics of relevance to the meeting will include 1) Observational studies of the maintenance of the quasi-stationary components of the flow, 2) Dynamical and simple model studies of forced motion, 3) Systematic errors in NW P systems, 4) Systematic errors in general circulation models, and 5) Sensitivity studies of the response of the stationary components to different aspects of the numerical models.

Abstracts of papers should be sent no later than 18 March 1983 to either: A. Hollingsworth, European Centre for Medium-Range Weather Forecasts, Shinfield Park, Reading, Berks., England RG2 9AX; or R. Sadourny, Centre National de la Recherche Scientifique, Lab. de Meteorologie Dynamique, Ecole Normale Superieure, 24 rue Lhomond, 75231 Paris, Cedex 05, France. Authors will be notified of acceptance by 6 May 1983.

For further details, contact A. Hollingsworth at the address above.

Call for Papers

2IST CONFERENCE ON RADAR METEOROLOGY, SE PTEMBER 19-23, 1983, EDMONTON, ALTA., CANADA

The 21 st Conference on Radar Meteorology, sponsored by the American Meteorological Society, will be held 19-23 September 1983 at the Chateau Lacombe in Edmonton, Alta., Canada. 
Papers on all aspects of radar meteorology are invited. A special session on the worldwide state of radar meteorology will be held, with invited papers from various countries.

Titles and reviewer's abstracts (200-400 words) should be submitted by 15 January 1983 to the Program Chairman: Dr. I. Zawadzki, Univ. du Quebec a Montreal, Dept. de Fhysique, C.P. 8888, Succ. A, Montreal, Que., Canada H3C 3 P8 (tel: 514-282-3320). Be sure to include the complete mailing address of the senior author. Authors will be notified of acceptance by 15 February 1983. Before submitting abstracts, see "New Meeting Procedures for Authors" following the list of meetings at the beginning of this section.

A preprint volume will be prepared and distributed only to preregistrants (in U.S. and Canada) before the meeting. Other conference participants will receive the preprint volume at the time of registration. Authors of accepted papers must submit complete camera-ready texts to AMS by 1 June 1983. Papers should not exceed 8 pages including diagrams and tables. Page charges will be assessed to help defray printing costs. Instructions and special typing paper will be furnished for manuscripts.

\section{Call for Papers}

INTERNATIONAL TECHNICAL CONFERENCE ON MITIGATION OF NATURAL HAZARDS THROUGH REALTIME DATA COLLECTION SYSTEMS AND HYDROLOGICAL FORECASTING, SEPTEMBER 19-23, 1983, SACRAMENTO, CALIF.

An International Technical Conference on Mitigation of Natural Hazards through Real-Time Data Collection Systems and Hydrological Forecasting will be held 19-23 September 1983 in Sacramento, Calif. The conference is organized by the World Meteorological Organization, the National Oceanic and Atmospheric Administration, and the California Department of Water Resources. AMS is a cooperating society.

The conference will focus on the real-time collection and application of hydrometeorological data in conjunction with hydrologic forecasting systems, and the use of such systems to mitigate natural hazards of importance to hydrology. State-of-the-art technologies including mini- and micro-computer systems, effective data reporting systems, and their cost effective integration into hazard mitigation systems are of particular interest. Location of the meeting on the same premises as the California-Nevada River Forecast Center, originators of the "Sacramento" rainfall-runoff model and on-line "Event Reporting Data Systems," will permit on-site examination of operating systems which are of direct relevance to the subject of the conference.

U.S. participants should send abstracts no later than 15 January 1983 to the Conference Coordinator: Robert J. C. Burnash, California-Nevada River Forecast Center, National Weather Service/NOAA, Room 1641, 1416 Ninth St., Sacramento, Calif. 95814 (tel: 916-442-1201; FTS. 448-2462). Abstracts from outside the United States are due 1 January 1983 and should be addressed to: The Secretary-General, World Meteorological Organization, Case Postale No. 5, CH-1211 Geneva 20, Switzerland. Additional information concerning the conference may be obtained from the above sources.

\section{Call for Papers}

SECOND INTERNATIONAL MEETING ON STATISTICAL CLIMATOLOGY, SEPTEMBER 26-30, 1983, LISBON, PORTUGAL

The Second International Meeting on Statistical Climatology will be held 26-30 September 1983 in or near Lisbon, Portugal. Plans for the conference are being formulated by an International Organizing Committee under the chairmanship of Dr. Allan H. Murphy (USA). It is anticipated that the meeting will be sponsored by several national and international organizations, including both meteorological and statistical societies. The conference will follow the 44 th Session of the Internatinal Statistical Institute to be held 12-22 September 1983 in Madrid, Spain. The principal host organization in Portugal is the National Institute of Meteorology and Geophysics. English will be the official language of the meeting.

The scientific program will focus on topics related to the application of statistical methods in climatology and the statistical analysis of climate data (the use of statistical methods in short-range weather forecasting will not be treated at this conference). Both invited and contributed papers will be included in the program. Suggestions concerning individuals who should be considered as potential invited speakers are welcome. The Organizing Committee is specifically seeking papers on the following topics: 1) design of climatological networks; 2) probabilistic and statistical models of climatological data; 3) time series analysis and spectral analysis of climatological data; 4) new techniques in statistical analysis of climatological data; 5) statistical climate prediction; 6) statistical analysis of climate simulation experiments; 7) Bayesian statistics in climatology; 8) statistical methods in climate impact assessment and in applications of climatological data; and 9) value and use of climatological data. A preprint volume containing the invited and contributed papers to be presented at the meeting will be prepared and made available to all conference participants.

Individuals who would like to submit a paper for consideration for inclusion in the conference program should send two copies of both a reviewer's abstract and a publication abstract prior to 26 November 1982 to $\mathrm{Dr}$ Murphy at the address below. The reviewer's abstract should be written in an informative manner and should be approximately 400-500 words in length (the decision to accept or reject the paper will be based on this abstract). A short publication abstract not exceeding 125 words in length is also required for possible inclusion in the preprint volume and/or in an abstracts booklet. Contributors will be notified in January 1983 concerning the acceptance or rejection of their papers. At that time, authors of papers accepted for presentation at the meeting will be provided with information regarding the preparation and deadline for receipt of the ir manuscripts.

For further information concerning plans for the meeting and conference program, please contact Dr. Murphy at the following address: Dept. of Atmospheric Sciences, Oregon State Univ., Corvallis, Oreg. 97331, USA (tel: 503-754-4557).

The Organizing Committee consists of: A. H. Murphy, Chairman; and O. Essenwanger, E. L. Scott, R. Sneyers, E. Suzuki, and E. Wegman.

\section{Call for Papers}

FIFTH CONFERENCE ON HYDROMETEOROLOGY, OCTOBER 18-20, 1983, TULSA, OKLA.

The Fifth Conference on Hydrometeorology, sponsored by the American Meteorological Society, will be held 18-20 October 1983 in Tulsa, Okla. The conference is being organized by the AMS Committees on Hydrology and Severe Local Storms and will be held in conjunction with the 13th Conference on Severe Local Storms. The AMS Central Oklahoma Chapter will be the local host.

As you probably realize, the 1980s have brought diminished financial resources to the hydrometeorological community. Hence, this conference will focus on "The Best Mix--The Integration of Data Sources and Models to Optimize Hydrometeorological Information." A key conference objective will be to foster even more cooperation between hydrologists, climatologists, and meteorologists. Can we not speak the same language and more efficiently exchange data?

Therefore, papers are being solicited on the following topics 1) Water management in relation to hydro- 
meteorology, 2) End users/Emergency preparedness, 3) Problems with interfacing meteorological and hydrological models, 4) Rainfall and stream forecasting, and 5) Flash floods. A few invited papers and a Horton Memorial Lecture will help focus on the conference theme.

In addition, at least two sessions will be held jointly in midweek with the 13th Conference on Severe Local Storms. Subject areas of joint interest include: 1) Network (hence, data) requirements and 2) Forecast techniques (case studies, climatological analogs, and other operationally oriented problems).

The Program Committee strongly encourages authors to concentrate on one or two key thoughts in each article: Our desire is to enhance the quality of presentations and figures at the conference. To this end, we would hope that 15-20 minutes could be made available to each author for presentations and questions. Thus, the Program Committee may have to exercise the right to reject papers that appear irrelevant, unsound, duplicative, or uninformative. At the conference, authors should be prepared to concisely present: 1) a statement of the problem, 2) the problem's relation to hydrometeorology, 3) the analysis, and 4) the resul ts.

Titles and articulate, succinct abstracts of 400 words should be submitted by 15 March 1983 to both Program Co-Chairmen: Dr. Kenneth C. Crawford, NWS Forecast Office, P.O. Box 59997, Oklahoma City, OKla. 73159; and Mr. William I. Pugsley, Chief, Hydrometeorology Div., Canadian Climate Centre, 4905 Dufferin St., Downsview, Ont., Canada M3H 5T4. Inclusion of a key figure or two and a longer reviewer's abstract is encouraged. Before submitting abstracts, see "New Meeting Procedures for Authors" following the list of meetings at the beginning of this section. Authors will be notified regarding acceptance.

Instructions and special typing paper for manuscripts will be furnished to authors of accepted papers in early May. Complete camera-ready texts of no more than 8 pages, including diagrams and tables, must be submitted to AMS by 15 June 1983. Page charges will be assessed to help de fray printing costs. A preprint volume will be prepared and distributed only to preregistrants (in U.S. and Canada) before the meeting. Other conference participants will receive the preprint volume at the time of registration.

\section{Call for Papers}

FIFTH CONFERENCE ON ATMOSPHERIC RADIATION, OCTOBER 31-NOVEMBER 3, 1983, BALTIMORE, MD.

The Fif th Conference on Atmospheric Radiation, sponsored by the American Meteorological Society, will be held 31 October-3 November 1983 in Baltimore, Md. This conference is intended to provide a forum for exposition and discussion of all aspects of atmospheric radiation including remote sensing.

Papers are solicited in, but not limited to, the following areas. 1) radiative transfer in realistic atmospheres, 2) radiation budget studies, 3) remote sounding of the atmosphere, 4) radiation and climate modeling, 5) cloud and radiation, 6) radiative effects of aerosols and gases including infrared spectroscopy, 7) radiation instrumentation and measurements, and 8) solar energy applications. The solar energy area will be cosponsored by the Solar Radiation Division of the American Solar Energy Society. There will be a number of invited papers in each area.

Titles and abstracts (about 100 words) of contributed papers, suitable for selection and program organizational purposes, should be sent by 1 April 1983 to the Program Co-Chairman Prof. K. N. Liou, Dept. of Meteorology, Univ. of Utah, Salt Lake City, Utah 84112 (tel: 801-581-6136). Authors will be notified regarding acceptance of their papers by 1 May 1983. Before submitting abstracts, see "New Meeting Procedures for Authors" following the list of meetings at the beginning of this section.

Instructions and special typing paper will be furnished by
AMS to authors of accepted papers. A complete camera-ready extended abstract of no more than 4 pages (8 pages for invited papers), including diagrams, must be received at AMS headquarters no later than 15 July 1983. Page charges will be assessed to help defray printing costs. A preprint volume of extended abstracts will be prepared and distributed to preregistrants before the meeting. Other conference participants will receive the preprint volume at the time of registration.

\section{Call for Papers}

EIGHTH CONFERENCE ON PROBABILITY AND STATISTICS IN ATMOSPHERIC SCIENCES, NOVEMBER 16-18, 1983, HOT SPRINGS, ARK.

The Eighth Conference on Probability and Statistics in Atmospheric Sciences, sponsored by the American Meteorological Society, will be held 16-18 November 1983 in Hot Springs, Ark. The conference will be held concurrently with the Third Conference on Applied Climatology, and a joint session is planned.

The conference will cover all aspects of the use of probability and statistics in the atmospheric sciences. The term "probability and statistics" is interpreted broadly to encompass related fields such as decision analysis. Review papers that deal with new developments in statistics and their potential application to the atmospheric sciences are especially solicited.

The theme of the joint session with the Third Conference on Applied Climatology is the use of probability and statistics in the application of data and other information on climate to operational problems. Examples of these problems in areas such as agriculture, energy, and water resources include modeling of crop yields and calendars, solar and wind energy feasibility studies, and engineering design for extreme values of precipitation, temperature, or wind. Papers that address the issue of how to summarize climatic data in a form appropriate for decision makers are especially welcome.

To accelerate processing by the Program Committee, four (4) copies of titles and 200-400 word reviewer's abstracts should be submitted by 15 April 1983 to the Program Chairman: Dr. Richard W. Katz, Dept. of Atmospheric Sciences, Oregon State Univ., Corvallis, Oreg. 97.331 (tel: 503-754-4557). Please indicate if the paper is to be considered for the joint session, and send an additional copy to $\mathrm{Dr}$. Wayne $\mathrm{M}$. Wendland at the address given in the following "Call for Papers." The reviewer's abstracts should concisely present: 1) statement of problem, 2) importance to advancement of statistics as applied to atmospheric sciences, 3) approach, and 4) results. Before submitting abstracts, see "New Meeting Procedures for Authors" following the list of meetings at the beginning of this section.

Instructions and special typing paper will be furnished to the authors of accepted papers. A complete camera-ready manuscript of no more than 8 pages, including figures and tables, must be received at AMS headquarters no later than 15 July 1983. Page charges will be assessed to help defray printing costs. A preprint volume will be prepared and distributed only to preregistrants (in U.S. and Canada) before the meeting. Other conference participants will receive the preprint volume at the time of registration.

\section{Call for Papers}

THIRD CONFERENCE ON APPLIED CLIMATOLOGY, NOVEMBER 16-18, 1983, HOT SPRINGS, ARK.

The Third Conference on Applied Climatology, sponsored by the American Meteorological Society, will be held 16-18 November 1983 in Hot Springs, Ark. The AMS Committee on Applied Climatology is organizing the program. The conference will be held concurrently with the Eighth Conference on Probability and Statistics in Atmospheric Sciences, and a joint session is planned. 
Abstracts of 100 words or less are invited for consideration and should be sent no later than 15 April 1983 to the Program Chairman: Dr. Wayne M. Wendland, Illinois State Water Survey, P.O. Box 5050, Station A, Champaign, Ill. 61820 (tel: 217-333-0729). Before submitting abstracts, see "New Meeting Procedures for Authors" following the list of meetings at the beginning of this section.

Papers submitted for the joint session must be of interest to both conferences (e.g., statistical aspects of climatic data and related information), and will be published in the preprint volume of the Eighth Conference on Probability and Statistics in Atmospheric Sciences. See preceding "Call for Papers" on how to submit abstracts for the joint session.

Further information, including session topics, will be announced in future issues of the BULLETIN.

INTERNATIONAL CONFERENCE ON BIOMETEOROLOGY, NOVEMBER 27-30, 1983, NEW DELHI, INDIA

An International Conference on Biometeorology will be held 27-30 November 1983 in Vigyan Bhavan, New Delhi, India. The conference is sponsored by the International Society of Biometeorology and the Department of Environment and the National Council of Meteorology of the Government of India.

Focus will be on the role of biometeorology in optimized development in the fields of Management of natural grazing land, aquatic, and forest ecosystems; Optimized crop production; Animal nutrition and productivity; and Human health and efficiency. Other topics planned for the conference are identification of specific action programs in the above fields and all topics with special consideration to the conditions in developing countries.

For further details, please write to: Dr. S. C. Pandeya, Organizing Secretary, International Conference on Biometeorology, Dept. of Biosciences, Saurashtra Univ., RAJKOT 360005 , India.

Extended Abstracts

FOURTH CONFERENCE ON ATMOSPHERIC RADIATION

June 16-18, 1981

Toronto, Ontario, Canada

\section{Session Topics include:}

Inversion Methods-

Temperature Profile

Remote Sensing of Minor

Constituents

Solar Energy

Radiative Transfer Studies

Radiative Properties and Effects of Aerosols

Radiation Budget

Instrument Studies

Theoretical-Numerical Cloud Studies

Analysis of Cloud Observations

Climate Applications

$\$ 15 /$ Members; $\$ 20 /$ Nonmembers (plus $\$ 2.00$ postage/handling)

$$
254 \text { Pages }
$$

Send order and remittance to:

American Meteorological Society 45 Beacon St., Boston, MA 02108

\section{Second Conference on Flash Floods}

\author{
March 18-20, 1980 \\ Atlanta, $\mathrm{Ga}$.
}

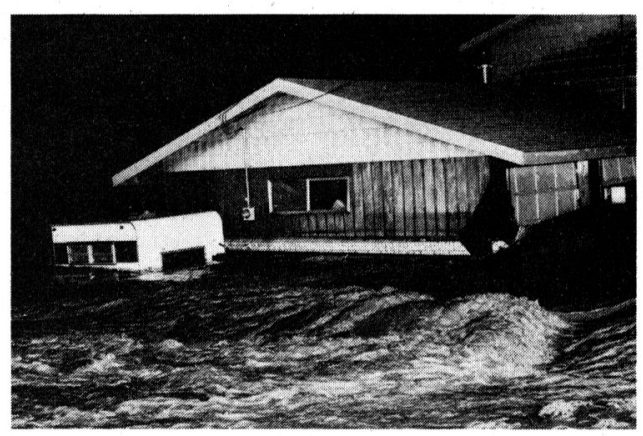

\section{Preprints}

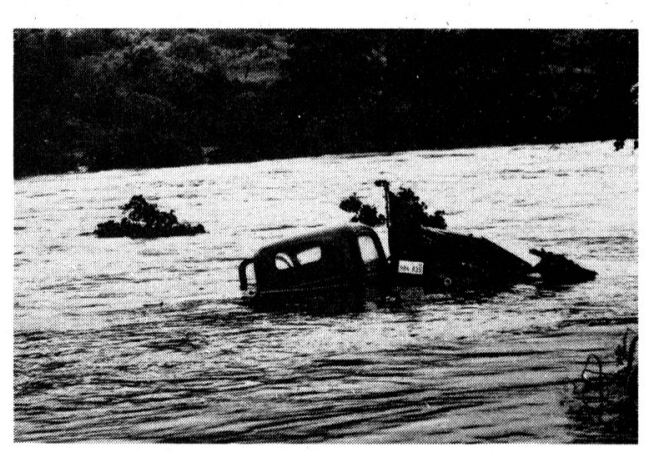

The Second Conference on Flash Floods, sponsored by the American Meteorological Society, was held 18-20 March 1980 in Atlanta, Ga. The volume contains 45 papers arranged under the following session topics:

Case studies of recent flash floods - Human response - Climatology - Satellite and radar applications - Forecasting techniques - Operations - Warning systems - Forecast delivery and utilization systems

258 pages $\$ 15$ AMS Members
$\$ 20$ Nonmembers
(add \$2.00 postage and handling)

Send order and remittance to:

AMERICAN METEOROLOGICAL SOCIETY 45 Beacon St., Boston, Mass. 02108 